\title{
O pensamento decolonial no horizonte de combate à violência epistemológica e/ou ao epistemicídio no ensino de História
}

\author{
Decolonial thinking in the horizon of combating epistemological violence and/or \\ epistemicide in the teaching of History
}

Elison Antonio Paim

Professor Adjunto do Centro de Educação da Universidade Federal de Santa Catarina

(CED-UFSC)

elison0406@gmail.com

\section{Helena Maria Marques Araújo}

Professora Associada do Instituto de Aplicação F.R.S.da Universidade do Estado do Rio de Janeiro(CAp

$-U E R J)$

hmaraujo.maosaobra@gmail.com

\begin{abstract}
Resumo: Este artigo se baseia em pesquisas frutos de experiências de mais de trinta anos de magistério na Educação Básica e formação de professores nos convidando a posicionamentos frente ao currículo de ensino de História escolar, das licenciaturas e pósgraduações. Identificamos desafios como o eurocentrismo do conhecimento e currículos e a violência epistemológica e/ ou epistemicídio sofrido por grupos subalternizados que atingem especialmente as Ciências Humanas. Desenhamos uma cartografia de matriz curricular decolonial e intercultural crítica apontando através de brechas decoloniais (WALSH, 2016) a possibilidade de busca por maior justiça social e epistemológica nos livros didáticos e aulas de História, assim como em nossa Aby Ayalla. Em expedições acadêmicas trilhamos um caminho teóricometodológico que possibilite um enfrentamento mais eficaz contra tais opressões e silenciamentos construindo memórias e histórias insurgentes.
\end{abstract}

Palavras-chave: ensino de História, decolonialidades, violência epistemológica.

\begin{abstract}
This article is based on research resulting from experiences of more than thirty years of teaching in Basic Education and teacher training, inviting us to take a stand in relation to the curriculum for teaching history in schools, undergraduate and graduate degrees. We identified challenges such as the eurocentrism of knowledge and curricula and the epistemological violence and/or epistemicide suffered by subalternized groups that especially affect the Human Sciences. We designed a critical decolonial and intercultural curriculum cartography pointing through decolonial gaps (WALSH, 2016) to the possibility of seeking greater social and epistemological justice in textbooks and history classes, as well as in our Aby Ayalla. In academic expeditions, we follow a theoretical-methodological path that enables a more effective confrontation against such oppression and silencing, building insurgent memories and histories.
\end{abstract}

Keywords: teaching history. decolonialities, epistemological violence. 
Chego e rimo o rap guarani e kaiowá

Você não consegue me olhar

E se me olha não consegue me ver Aqui é o rap guarani que está chegando pra revolucionar

O tempo nos espera e estamos chegando Por isso venha com nós

Refrão (2x):

Nós te chamamos pra revolucionar Por isso venha com nós, nessa levada

Nós te chamamos pra revolucionar

Aldeia unida, mostra a cara

(Eju Orendive -

Brô Mc's)

\section{Um horizonte e um ponto de chegada}

O Brô Mcs é o primeiro grupo de rap indigena do Brasil e foi criado por quatro indígenas Guarani e Kaiowás há mais de uma década, embora tão pouco conhecidos e ouvidos pela maioria dos brasileiros. O quarteto é composto por dois pares de irmãos: Kelvin e Charlis Peixoto e Clemerson Batista e Bruno Veron. ${ }^{1}$ Em suas letras eles falam da vida e denunciam os sofrimentos e exploração sofrida pelos indígenas Guarani e Kaiowás no Mato Grosso do Sul - que é o estado com a segunda maior população de indígenas do Brasil - e que tem um enorme rebanho de gado bovino e grandes latifúndios do agronegócio, daí os conflitos de terras serem tão cruciais e viscerais.

Quando pensamos no ensino de História em todas as décadas de exercício do magistério e de nossa formação acadêmica no mínimo nos sentimos incomodados com tantos silenciamentos e ausências na historiografia escolar mais clássica, assim como nos cursos de licenciatura e pós-graduações em geral. Como na letra de Brô Mc`s -Você não consegue me olhar. E se me olha não consegue me ver - muitas vezes nos deparamos com memórias subterrâneas em que precisamos ter coragem de escovar a história a contrapelo como nos sugere Walter Benjamin (1994) para olhá-las, enxergálas e narrá-las. Quantos grupos subalternizados foram apagados dos livros de História acadêmicos e escolares, quantas histórias e memórias contra-hegemônicas foram marginalizadas de nosso discurso historiográfico oficial e/ou escolarizado? A quem dizem respeito tais memórias e histórias silenciadas? A quem interessa silenciá-las? Por que não narrá-las? Quantas assimetrias epistemológicas os grupos indígenas e

\footnotetext{
1 Veja mais em https://www.uol.com.br/ecoa/colunas/arte-fora-dos-centros/2020/05/28/onde-passa-aboiada-aldeias-de-dourados-resistem-a-pandemia-e-agronegocio.htm?cmpid=copiaecola
} 
afrodescendentes sofreram e sofrem quando suas histórias e memórias são relatadas apenas de forma complementar ou em anexos aos capítulos dos livros didáticos que tratam de escravização e do epistemicídio de indígenas na América Latina pré-colonial?

Onde estão ancoradas as memórias dos povos indígenas hoje em dia? Por que na história da luta pela terra nos livros de História do Brasil pouco se constrói a partir dos indígenas e de suas resistências, assim como dos camponeses? Por que os heróis negros ou indígenas ainda causam estranhamento à maioria dos brasileiros? Por que até hoje a maioria da população brasileira que estudou história nos bancos escolares não se envolve nas lutas e resistências indígenas enxergando-os como os primeiros donos das terras tupiniquins? Por que não ouvimos rappers indígenas e a existência destes ainda nos surpreende? Como e por que continuar ignorando os indígenas urbanos, por exemplo da Aldeia Maracanã $\tilde{2}^{2}$ no Rio de Janeiro e inúmeros outros? Por que queimar uma escola e centro de estudos medicinais em terras Xacriabá? ${ }^{3}$

\footnotetext{
2 PITASSE, Mariana (2019). Saiba mais sobre a Aldeia Maracanã, alvo de ataques no Rio: Aliado de Bolsonaro, o deputado estadual eleito fez declarações de ódio contra indígenas na última semana. Brasil de Fato. Rio de Janeiro (RJ), 09 de Janeiro às 05:00. Disponível em: https://www.brasildefatorj.com.br/2019/01/09/saiba-mais-sobre-a-aldeia-maracana-alvo-de-ataques-norio . Acessado em 24 de jun. 2021 ás 12:04. A autora nos informa que a Aldeia Maracanã está "Localizada na zona Norte da cidade do Rio de Janeiro, a aldeia urbana foi erguida por indígenas de diferentes etnias, em 2006, no terreno onde era abrigado o antigo Museu do Índio. Muito se falou sobre a aldeia, em 2013, quando o terreno foi alvo de disputa a partir da intenção do governo do estado do Rio de derrubar o prédio para construção do Complexo do Maracanã, que receberia partidas da Copa do Mundo de 2014" e na sequência apresenta trecho da fala do cacique José Urutau afirmando que "Vieram mexer com a nossa espiritualidade, esse local é um patrimônio espiritual para a gente. Aqui viviam os povos Maracanã e Tupinambá, era um grande aldeamento. Nós não viemos até o Maracanã, a cidade que veio até nós. A cidade é um grande cemitério indígena que nos engoliu. Nós aqui não temos estrutura
} nenhuma, mas seguimos lutando".

${ }^{3}$ Conforme postagem de Célia Xacriabá em 24 de junho de 2021 disponível em: https://www.instagram.com/p/CQf7ibxHpWW/ "Com uma tristeza muito grande e coração cheio de dor que nesta madrugada recebemos a notícia e as cenas da nossa escola Xukurank na terra Indígena Xakriabá sendo queimada, a nossa Aldeia, as pessoas a frente da direção da escola, mas toda comunidade escolar que sabe o quanto significa está profundamente triste em clima de velório, podem nos perguntar, mas morreu alguém? E quem disse que em partes não sentimos assim, porque o que fizeram foi colocar fogo na história e trajetória da vida de cada um. Lugar onde construir minha vida toda a trajetória escolar desde os seis anos de idade, lugar onde ainda criança vi muitas lideranças e professores, professoras reunirem, pra avançar na luta pela educação, pelo direito, a escola foi um chão que levou a importante decisões e conquistas, mas como alguém pode cometer tamanha crueldade? Quem não respeita a luta pela construção coletiva investida em um passado, vai conseguir construir algum futuro melhor? Estamos vivendo em cortina de fumaça os direitos Indígenas sendo saqueados, ontem acabaram de votar PL 490 que anula a Demarcação dos Territórios Indígenas já não basta cenário de guerra, precisa provocar outras guerras? Pegaram em um ponto que vai prejudicar a vida não é somente de quem trabalha na escola, todo mundo a escola vai ter dificuldade de caminhar sem a vida documental de cada criança de cada pessoa que precisar, de um jovem que querer sair pra estudar, todo mundo que tem trajetória escolar. Mesmo que reconstrua a estrutura os arquivos material não serão recuperados de histórico, somente aqueles que estão no sistema. Mas não é sobre isso exatamente é como pode destruir a história da luta que tinha forte legado ali na educação, as pessoas que não sentem sensibilizados com a luta a história Coletiva não percebe que queimou a vida de muitas pessoas juntas e comemora uma ação criminosa de atentado deste não pode ter um projeto que preserve a vida e a construção de caminhos melhores". 
Tantas inquietações e indagações são angústias geradoras de perguntas e buscas de caminhos para que possamos se não acabar, pelo menos minimizar as violências epistemológicas cometidas durante séculos de exploração pelo colonialismo, e ainda hoje pelo neoliberalismo, patriarcado, homofobias e racismo estrutural. Muitas vezes podemos afirmar que a ocultação de lutas, resistências, valores, formas de vida, dentre outros aspectos são tão violentos, que pratica-se o que Boaventura Souza Santos (2010) denomina epistemicídio, ou seja, o assasinato das memórias ancestrais de povos indígenas e afro diaspóricos e de tantos outros grupos subalternizados.

Este artigo convoca reflexões e tomadas de posição frente a um mapeamento de uma cartografia decolonial e intercultural crítica que aponta a partir de nossos estudos e pesquisas e uma luta nevrálgica por maior justiça social e epistemológica nos livros didáticos e nas aulas de história, assim como na vida, nas cidades e nos campos, neste país e em nossa Aby Ayalla ${ }^{4}$. Segundo Santos (2007) para que haja uma verdadeira justiça social tem de haver justiça epistemológica. Por isso, nos propusemos a refletir como buscar um caminho teórico-metodológico que nos possibilite um enfrentamento mais eficaz contra essa violência epistemológica e até mesmo epistemicídio em relação às memórias e histórias quer nos livros escolares de História, quer na formação de professores ou em nossas aulas na Educação Básica e no Ensino Superior.

\section{O pensamento decolonial e intercultural como ponto de partida e no processo sentipensar}

Acreditamos que esse debate sobre violência epistemológica ou epistemicidio e memoricidio, ou seja, o assassinato de memórias, podem ser minimamente enfrentadas através de currículos críticos, particularmente estamos nos referindo à construção de um currículo decolonial e intercultural crítico de História. Sendo assim, o que seria um currículo de ensino de História decolonial e intercultural na Educação Básica? Quando e

\footnotetext{
4 PORTO-GONÇALVES (s/d). Segundo o autor, "ABYA YALA, na língua do povo Kuna, significa Terra madura, Terra Viva ou Terra em florescimento e é sinônimo de América. O povo Kuna é originário da Serra Nevada, no norte da Colômbia, tendo habitado a região do Golfo de Urabá e das montanhas de Darien e vive atualmente na costa caribenha do Panamá na Comarca de Kuna Yala (San Blas). Abya Yala vem sendo usado como uma autodesignação dos povos originários do continente como contraponto a América. A expressão foi usada pela primeira vez em 1507, mas só se consagra a partir do final do século XVIII e início do século XIX, por meio das elites crioulas, para se afirmarem no processo de independência, em contraponto aos conquistadores europeus. Muito embora os diferentes povos originários que habitam o continente atribuíssem nomes próprios às regiões que ocupavam Tawantinsuyu, Anahuac, Pindorama - a expressão Abya Yala vem sendo cada vez mais usada pelos povos originários do continente objetivando construir um sentimento de unidade e pertencimento".
} 
quais aspectos nos permite dar um carimbo de currículo decolonial no ensino de História na Educação Básica?

Primeiramente, estabelecemos parâmetros para denominarmos o que é currículo. Precisamos desnaturalizar o currículo como algo que é dado pronto. O currículo que vem proposto pela Base Nacional Comum Curricular - BNCC, que está tão em voga, é tão polêmico na nossa área ${ }^{5}$. Precisamos construir currículos outros, currículos contra hegemônicos, poderíamos pensar um currículo crítico na linha freireana, construirmos um currículo montado em projetos ou em Célestin Freinet $(1973 ; 1998)$ nas aulas passeio, por exemplo. Mas centramos esta escolha num dito currículo decolonial. O que estamos afirmando primeiramente é que há vários e extremamente importantes currículos críticos que não são decoloniais. Por que? Porque podemos ter currículos contra hegemônicos, propositivos, que não necessariamente sejam decoloniais. É claro que o contrário é diferente. Um currículo decolonial, sempre é crítico, anticapitalista, antirracista, anticolonialista, antihomofóbico. Mas nem todo currículo crítico é decolonial. Embora ele possa ser antirracista, anticolonialista e anticapitalista. Chegamos ao ponto que queremos debater. Então, o que é um currículo decolonial?

Partiremos da dimensão educativa da memória (ARAÚJO, 2017) na construção desse currículo decolonial, ou seja, a memória enquanto princípio educativo porque esse seria um fio condutor desse currículo decolonial que vamos priorizar na proposta do ensino de História decolonial, do currículo de História decolonial. Antes de conceituarmos o que são decolonialidades e educação intercultural crítica, vamos pensar nesse currículo e nessa memória. O currículo, segundo Tomaz Tadeu [da Silva] (2005), é uma arena política de disputas de visões de mundo, de ciência, de saberes, de valores e de cultura. Então, começamos a diferenciar um primeiro princípio que o currículo não é neutro. O currículo é uma escolha e é uma seleção que mostrará diversas visões de ciência, de mundo, de culturas e de valores. Sendo assim, entendemos que se temos um currículo que foi construído oficialmente, hegemonicamente, soberanamente, também podemos desconstruir esse currículo e criar um outro currículo com outras memórias, com outras histórias não dominantes, não oficiais referenciadas nos grupos subalternizados, nas histórias e memórias subterrâneas (POLLAK, 1989). Memórias estas que estão no subterrâneo, que estão escondidas, que foram invisibilizadas pelas histórias e memórias oficiais. São estas as memórias e histórias outras de grupos

\footnotetext{
5 Sobre isso leia artigo dos professores da Universidade Federal do Rio Grande do Sul: PEREIRA \& RODRIGUES (2018).
} 
subalternizados. Que grupos são esses? Os afrodescendentes, ameríndios, ribeirinhos, LGBTQI $[\mathrm{A}+]^{6}$, caiçaras, quilombolas, todos aqueles povos que tiveram sua história e suas memórias invisibilizadas, silenciadas pelo poder hegemônico e por histórias e memórias hegemônicas.

Entendido isso, começamos a pensar que o currículo é essa competição num microcosmo político, ideológico e pedagógico, onde os conteúdos oficiais travam embates com as próprias partes do currículo que podem ser produzidas na escola pelos professores e professoras, pelos/as estudantes, pelos/as estagiários/as, os currículos reais.

E a memória? Se perguntarmos o que é memória no senso comum, e quando falamos que um indivíduo perdeu a memória, significa que ele perdeu sua identidade, sua autonomia, sua essência, porque ele não lembra de nada. Se fizermos uma correlação com os povos, uma sociedade que perde sua memória, perde sua autonomia e seu horizonte para onde ir e de onde veio. ${ }^{7}$

Paul Ricœur (2007) chama de memória justa, as memórias felizes. Como podemos ter um currículo decolonial com histórias e memórias mais justas? Histórias e memórias que contemplem esses grupos subalternizados, que foram durante séculos esquecidos, invisibilizados, explorados e expropriados pelo poder do colonizador e depois no caso brasileiro pelos poderes das elites imperiais, republicanas e atuais onde ainda presenciamos tal embate. Mais do que nunca na nossa sociedade, as guerras de histórias e memórias estão em evidência. Quais são as memórias da pandemia que queremos perpetuar e construir? São as dos grupos invisibilizados gritando por socorro, por vacina, por auxílio emergencial ou as do governo dizendo que já fez tudo que podia e, que, se a pandemia está matando é um problema da virulência do vírus, mas não há mais nada a fazer. Isto é uma guerra de memórias e de histórias que tem consequências, muitas vezes, trágicas nas nossas vidas pessoais e coletivas. Então, o tempo todo essa arena política como defende Tomaz Tadeu da Silva (2005) nos coloca em evidência, e nós como historiadores e [historiadoras], professores [e professoras] de História

\footnotetext{
6 LGBTQIA+ significa em cada letra: Lésbicas, Gays, Bissexuais, Transexuais, Queer, Intersexo e Assexual. Este é um movimento político e social em defesa do respeito à diversidade sexual e suas representatividades e acesso aos direitos humanos e sociais.

${ }^{7}$ Memória aqui entendida como como vidência e êxtase conforme o pássaro sankofa africano, ou como os gregos antigos a entendiam. Os gregos diziam que com, a memória você olha para trás em vidência e êxtase, para em seguida você olhar o futuro, para projetar o futuro. É como o pássaro africano, a mesma analogia da cabeça para trás e os pés para frente, então olha para trás para poder andar para a frente, para um futuro melhor, mais feliz.
} 
selecionamos partes do currículo a serem ensinadas e partes que não teremos tempo para ensinar.

Os símbolos e as representações constituem as narrativas dominantes ou hegemônicas (HALL, 2016), como por exemplo, a bandeira e o hino para uma nação. As narrativas nacionais contemplam histórias, vitórias, derrotas e memórias que representam trunfos ou lutas significativas a um país, governo, Estado ou comunidade. Assim, os membros de uma nação devem se reconhecer em tais narrativas. Porém, se as histórias nacionais não contam as histórias e memórias ancestrais e vividas por grupos afro descendentes, ameríndios e outros subalternizados, não há como nossos estudantes nas escolas públicas, muitos [e muitas] afrodescendentes, ameríndios ou pertencentes a grupos populares, filhos e filhas de trabalhadores [e trabalhadoras] do campo ou da cidade se reconhecerem nessas narrativas nacionais que não contemplam histórias e memórias outras, não hegemônicas, histórias e memórias desses grupos subalternizados. O sociólogo britânico-jamaicano Stuart Hall afirma que é necessário encontrarmos na narrativa nossa alteridade, ou seja, nossa representatividade. Cotidianamente lemos histórias e memórias oficiais que nada dizem a respeito, ou pouco falam sobre negros, indígenas e mestiços, pois durante séculos - desde o XVI até o XIX - e em alguns lugares mesmo no século $\mathrm{XX}$, foram excluidos como povos atrasados que precisavam ser civilizados. As elites latino-americanas nos séculos XIX, XX e até no século XXI tem ideologias e práticas que excluem e procuram silenciar essa grande massa de populações que sofreram e sofrem os processos de exclusão provocados pelo colonialismo, patriarcado e capitalismo.

Nesse sentido, lembramos que os indígenas estão clamando, gritando por socorro no Brasil cada vez mais e pouco ainda se faz. Há pouco tempo foi apresentado no jornal na TV uma liderança indígena de Mato Grosso e um médico que atendia dentro do Parque do Xingu, um médico só. Com um grande número de indígenas doentes com COVID, não há condição! Continuamos vendo de outras formas esse massacre às populações indígenas. Também não é demais lembrar que as populações de favela no Rio de Janeiro sofrem violências aos Direitos Humanos em seus territórios cotidianamente. Em outros lugares do Brasil e em toda a América Latina com diversas populações como as populações amazônicas e ribeirinhas e com tantos outros grupos vemos acontecer violências físicas, simbólicas e epistemológicas cotidianamente.

Em contraposição, surgem as contra narrativas, que têm engendrado narrativas outras, narrativas contra hegemônicas. Aquelas contranarrativas se baseiam em 
afirmações e representações positivadas de povos de matriz africana e povos originários numa narrativa de nação. Portanto, pretendem desestabilizar as representações hegemônicas, oficiais, colocando no lugar narrativas alternativas de memórias e histórias dos grupos populares. É isso que queremos provocar com este artigo: que os leitores consigam produzir em suas aulas, suas pesquisas, narrativas que sejam decoloniais, que façam uma opção decolonial, que apresentem alternativas para grupos subalternizados às representações hegemônicas nacionais, regionais ou locais oficiais.

Tais narrativas hegemônicas, que excluem valores, saberes e fazeres, terminam por serem legitimadas na escola acaba sendo a legitimadora. Tendo em vista que quando a escola simplesmente reproduz os currículos oficiais, ela não cria memórias, não constrói histórias contra hegemônicas, então, ela continua permitindo que as minorias identitárias não se reconheçam nos currículos oficiais escolares. Daí a importância de usarmos o que Catherine Walsh (2017) chama de brechas/grietas decoloniais, ou seja, aproveitar onde está craquelado, onde há fissuras, onde há possibilidades de entrada, de insurgir o novo, o contrahegemônico, como por exemplo o curso oferecido pelo professor Arthur José Baptista ${ }^{8}$ sobre a cultura e história do povo Yorubá. Tal curso se configura como uma brecha decolonial em uma escola pública federal, que é o renomado Colégio Pedro II. É nessas brechas, grietas, que vemos a possibilidade de atuação insurgente, porque ainda vivemos em um mundo hegemonicamente capitalista, evidentemente com grande força do patriarcado e do racismo estruturais.

Dessa forma, a escola é ainda uma instituição excludente na maioria das vezes. Porém, há lugares em que temos como criar as brechas decoloniais. Podemos pensar que assim como nós estamos pensando e fazendo, há muitos professores que estão fazendo diferente dos currículos oficiais que excluem da narrativa nacional saberes, valores e fazeres desses grupos minoritários. Estes grupos são chamados minoritários, mas comportam grande números de pessoas que são consideradas minoritárias no acesso aos bens sociais, econômicos e educacionais, de saúde e, muitas vezes, de representatividade social. O que acontece na maioria das nossas escolas perpassa uma lógica desenvolvimentista e monocultural, que acaba permeando a maior parte dos nossos currículos.

\footnotetext{
8 Arthur José Baptista é mestrando no Profhistória - Mestrado Profissional de Ensino de História da UERJ, sendo orientado por Helena Maria Marques Araújo. Sua pesquisa consiste na análise das respostas dadas pelos estudantes que frequentaram um curso criado e oferecido por ele de cultura e mitologia yorubá durante vários anos, como curso de extensão no Colégio Pedro II na cidade do Rio de Janeiro.
} 
Para Boaventura (2007) o conhecimento europeu, ocidental, branco, cristão e heterossexual está permeado de monoculturas. Sendo então, o conhecimento acadêmico e escolar extremamente monocultural, pois prevalece a cultura dominante. Logo, valores, formas de vida, concepções de mundo, distribuição de riqueza, de terras, saúde, emprego e educação, dentre outros, são permeados por uma ideologia e cultura hegemônicas, muito embora saibamos que existe um hibridismo cultural (CANCLINI, 1997) permeando todas as classes sociais, não se constituindo como blocos monolíticos.

Porém, é na escola, nas nossas salas de aula que os jovens e crianças afrodescendentes e ameríndios não se sentem reconhecidos nesses currículos, se sentem excluídos, não vivem o sentipensar (BORDA apud ESCOBAR, 2014), não se sentem protagonistas da história e, muitas vezes, nem de sua própria história, vivendo uma imensa alienação no processo do sentipensar a própria vida. Vislumbramos no conceito de sentipensamento como nos coloca Arthur Escobar, baseado em Frans Borda, uma brecha decolonial para transformarmos os currículos em algo mais vivo e significativo para nossos estudantes, como os autores nos conceituam no trecho a seguir:

[...] también se inspiran en el concepto de sentipensamiento popularizado por el maestro Orlando Fals Borda (1986), y que aprendiera de las concepciones populares ribereñas de la Costa Atlántica. Sentipensar con el territorio implica pensar desde el corazón y desde la mente, o co-razonar, como bien lo enuncian colegas de Chiapas inspirados en la experiencia zapatista; es la forma en que las comunidades territorializadas han aprendido el arte de vivir. Este es un llamado, pues, a que la lectora o el lector sentipiense con los territorios, culturas y conocimientos de sus pueblos — con sus ontologías-, más que con los conocimientos des-contextualizados que subyacen a las nociones de "desarrollo", "crecimiento" y, hasta, "economía". (BORDA apud ESCOBAR, 2014: 16)

Por que nossos estudantes muitas vezes não se sentem representados nas escolas, nos currículos escolares ou nos livros didáticos? Eles não se percebem enquanto um sujeito histórico como nos fala Paulo Freire (2000), porque essa monocultura do currículo oficial é eurocêntrica, cristã, masculina, heteronormativa e ocidental. E tudo que se deixa do lado de fora, não está representado nesse currículo, logo precisamos pensar alternativas ao que é excludente, ao que silencia, ao que é injusto epistemologicamente e cognitivamente como nos diz o Boaventura (2007). Quando 
excluímos a memória ancestral dos povos afrodescendentes ou ameríndios, cometemos um epistemicídio, como o que vem sendo cometido há mais de quinhentos anos pela maioria de nossa cultura letrada e acadêmica. Mata-se a epistemologia de várias culturas africanas e dos afrodescendentes, a isso Boaventura denomina epistemicídio, o que se fez em toda a América Latina - Abi Ayala - inclusive com as populações brasileiras indígenas e afro diaspóricas.

Porém, vemos no horizonte mudanças, quando surgem cada vez mais grupos de rappers indígenas ou afrodescendentes, assim como outras transformações como a presença cada vez maior de um público em nossas aulas ou lives sobre decolonialidades e interculturalidade crítica. Mesmo nos cursos de graduação de História nos é frequentemente oferecido disciplinas completamente monoculturais e ocidentalizadas, não se apresentando uma visão dos povos latino-americanos dinâmica, dialética presente-passado e contemporânea, e sim, a partir do olhar dos europeus ou estadunidenses sobre a história da América Latina. Os cursos de pensamento decolonial ou por ele permeados poderiam e podem provocar uma fissura no sistema, uma brecha decolonial que nos permite fraturar os currículos eurocêntricos e introduzir nos currículos escolares ou universitários reais cada dia mais justiça de memórias e histórias contra hegemônicas. Então, podemos produzir currículos para além dos previstos nos documentos oficiais, currículos emancipatórios e democráticos, que com certeza muitos já constroem no cotidiano das escolas e das universidades.

Esses currículos hegemônicos têm um eixo muito definido, que é um eixo de saber ocidental, científico e moderno, fruto da colonialidade do poder e do saber. Enrique Dussel (2016) - um dos fundadores do pensamento decolonial latinoamericano - afirma que a civilização moderna europeia/ocidental autodescreve-se como mais desenvolvida e superior, e isso dará forma à colonização e à grande maioria dos próprios movimentos latino americanos que a elite criolla ${ }^{9}$ toma a liderança. Aqui no Brasil as aristocracias rurais fazem a independência, mas mantém nas estruturas, a ideologia, o sistema econômico e político do colonizador no binarismo

\footnotetext{
9 As elites criollas, i é, filhos dos colonizadores europeus desenvolveram o que Walter Mignolo denominou de colonialismo interno. Neste, elas tomam como modelo padrão civilizacional a ser alcançado o modelo europeu, portanto não há rompimento com o modo de ser patriarcal, cristão, heterosexual, racista e calcado na branquitude mesmo com os movimentos pela independencia das colonias americanas. MIGNOLO, Walter (2000).
} 
colonial/patriarcal atravessadas pela hierarquização racial, agregando-se posteriormente ao capitalismo.

Por isso, é necessário nos despirmos do colonizador que habita em nós a cada dia e para isso, temos que praticar, vivenciar, sentipensar o que vários decoloniais chamam de vigilância epistemológica nas nossas práticas, não só nos nossos saberes. Por isso, Walsh (2013) e outros autores afirmam que a decolonialidade exige de nós uma postura política do micro ao macro. Então, temos que nos decolonizar em nossas vidas, até nas nossas relações de afeto, porque se não o fazemos, sem querer acabamos perpetuando o autoritarismo, a exclusão e vários outros detalhes. Muito embora saibamos que também muitas vezes não escapamos de todo do nosso tempo e das matrizes de todo um processo cultural e histórico por mais que decolonizemos! Portanto, também vamos abordar brevemente conceitos importantes ao pensamento decolonial como as colonialidades do poder, do saber, da natureza e do ser (ARAÚJO e PAIM, 2018; PAIM, 2016.).

Voltando aos nossos currículos, Boaventura (2010) define que existem cinco lógicas monoculturais que perpassam os currículos que criam espaços/tempos que legitimam a modernidade e excluem outros por desqualificação e por não reconhecimento, outras memórias e outras histórias. Ele classifica isto, como a monocultura do saber e do rigor científico, é a primeira e é a que mais nos interessa para problematizar currículo. A segunda seria a monocultura das temporalidades, é muito interessante, refere-se ao tempo único, o tempo linear, o tempo cartesiano da ordem e do progresso.

A monocultura da naturalização das diferenças é a terceira. Sobre esta podemos perceber que o parâmetro da igualdade não resolve o problema, pois não adianta tratar os estudantes com igualdade, precisamos aplicar o princípio da equidade, tratando diferente quem está em posição desvantajosa para poder alavancá-lo a uma maior igualdade social. Sendo assim, precisamos tratar a diferença como riqueza e não como problema, segundo Vera Candau (2011). Quando dizemos "aqui são todos iguais, não há diferenças", silenciamos tudo que não se encaixa nesse currículo hegemônico, masculino, cristão, heteronormativo e ocidental. Quem está fora da normatização é e se sente excluído. A criança do terreiro em um currículo absolutamente cristão e fechado, não se vê reconhecida, por exemplo. Stela Caputo (2012) estuda a educação nos terreiros, evidencia em suas pesquisas que a criança na escola não pode dizer que é do terreiro ou do candomblé, do Santo, porque ela será marginalizada. 
A quarta monocultura, segundo Boaventura, é a monocultura da universalidade. Sobre isso Quijano (2016) e Dussel (2016) aprofundam muito bem, quando evidenciam como a Europa se autodetermina universal, ou seja, o que é universal para nós é a história europeia ocidental e não contempla nem a Europa Oriental (por exemplo: em geral só falamos em sala de aula da Rússia, na Revolução Bolchevique). Não falamos da Lituânia, nem da Finlândia, normalmente falamos da Europa Ocidental clássica apenas. A quinta monocultura para Santos (2010) é a monocultura da produtividade capitalista, que permeia todo nosso sistema e estruturas institucionais, mas que neste texto não iremos nos deter.

\section{Diálogos interculturais e ecologia de saberes no processo teórico- metodológico decolonial na produção histórico escolar e acadêmica}

Como vimos no item anterior, Boaventura identifica cinco monoculturas no sistema em que vivemos e diz que precisamos transformar essas monoculturas em ecologias de saberes em prol de luta por justiça social e justiça cognitiva e logo pelo fim da violência epistemológica ou por sua minimização.

O que nos interessa mais neste artigo é abordar a monocultura do saber e do rigor científico. É o saber formal que torna válidos somente conhecimentos produzidos por meio de procedimentos da ciência moderna, a qual está calcada nessa visão eurocêntrica da modernidade e da racionalidade. Essa monocultura até hoje define os nossos currículos escolares e todas as outras formas de conhecimento, como as memórias ancestrais, não escritas, a história oral, que são muitas vezes vistas como senso comum. Daí a importância para nós, historiadores e historiadoras, da história oral. Quem trabalha com o Manual de história oral da Verena Alberti (2013) e outros pesquisadores, sabe que esses saberes foram sendo legitimados pela história oral, que durante muito tempo também não era considerada história por essa visão eurocêntrica. Então, podemos concluir que não existe um saber total, o saber é sempre relacional. Todo saber é parcial, incompleto e somente o diálogo entre esses diferentes saberes produz uma capacidade de se considerar a pluralidade de vivências, a pluriversidade.

O diálogo entre diferentes saberes está incorporado no que Vera Candau (2016) denomina como diálogo intercultural, que não necessariamente significa harmonia. Muitas vezes o diálogo entre diferentes culturas têm muita tensão, muita disputa por 
memórias e narrativas, mas é importante que ele seja feito também na escola, nos grupos, clubes, universidades, nos partidos políticos, em todos os lugares. Podemos dar como exemplo, o fato de muitas mulheres virem questionando, nos partidos políticos, o quanto essas estruturas partidárias eurocêntricas ainda são coloniais, portanto, patriarcais, discriminando-as nas estruturas partidárias.

Os currículos, portanto, têm saberes sociais e culturais trazidos de uma produção coletiva cotidiana, baseados no princípio da igualdade e no reconhecimento da diferença. Fazem com que diferentes conhecimentos sejam postos em diálogos, contribuindo para que se possa sair do lugar da monocultura do saber formal, que está na base das injustiças cognitivas e sociais. E é aí que o conceito de ecologia de saberes (SANTOS, 2010) permite a troca de diferentes saberes em diálogo e em maior igualdade ou menor assimetria política, social e econômica. É importante que os nossos currículos escolares contemplem diferentes saberes. O que estamos dizendo com isso é que a nossa intenção é mostrar que os currículos oficiais não são os únicos, e que as produções curriculares são possíveis com relações mais democráticas entre saberes, ampliando formas e possibilidades de se ver e pensar o mundo, trazendo formas de viver, de sentir, de estar, de olhar mais solidárias e empáticas para com as dores alheias.

A decolonialidade questiona as estruturas sociais, políticas e epistemológicas da colonialidade que está entranhada dentro de nós. Acabou a colonização, o colonialismo, com os movimentos de independência da América Latina, mas permanece entranhado a estrutura colonial na política, na economia, na sociedade, na ideologia, no racismo, na produção e validação de conhecimentos, na racialização das classes sociais. Porém, para ser decolonial tem que questionar essas estruturas sociais, políticas e epistemológicas da colonialidade, que estão baseadas em padrões de poder que se calçam na racialização do conhecimento eurocêntrico e na inferiorização de alguns seres humanos. Isso é fundamental para estarmos trabalhando mais diretamente com um currículo decolonial. Podemos fazer um trabalho crítico, emancipador, ter alguns diálogos com autores decoloniais, mas não necessariamente estar num caminho decolonial diretamente, podemos ter uma inspiração decolonial. Para estar em um caminho decolonial, é necessário trazer esses conceitos para o seu debate, elencá-los e estruturá-los no processo teórico-metodológico de produção de saberes.

Para Candau e Walsh, a educação intercultural crítica está intrinsecamente relacionada ao pensamento decolonial na educação. A diferença não é problema, como já foi afirmado anteriormente. Se queremos trabalhar na escola com pensamento 
decolonial, chamamos a educação intercultural crítica, porque esta promove processos sistemáticos de diálogo entre diferentes sujeitos individuais e coletivos (CANDAU, 2020.), que são saberes e práticas na perspectiva da afirmação da justiça social, da justiça econômica, cognitiva e cultural, assim como da necessidade e do desejo de se construir relações igualitárias entre grupos socioculturais. Ao produzirmos tais articulações estamos lutando pela democratização da sociedade através de políticas que articulam direitos da igualdade e direitos da diferença. Sobre essa perspectiva de articular direitos, Boaventura afirma que devemos ser tratados com igualdade, quando a igualdade nos dignifica e com diferença, quando a diferença não nos inferioriza (SANTOS, 2007). Portanto, não há certo ou errado, o processo não é maniqueísta e sim, dialético. Precisamos aprender a equilibrar as tensões entre igualdade e diferença dependendo dos contextos e das estruturas. Em alguns momentos ser tratado com igualdade é emancipador, em outros momentos pode nos derrubar, já em outros momentos a diferença nos enriquece e em muitos pode nos guetificar, depende da situação em que estivermos vivendo, ou analisando. Portanto, a interculturalidade crítica não só reconhece e integra culturas diferentes, mas visa promover o desequilíbrio ou até mesmo a implosão das estruturas coloniais (WALSH, 2016), ou seja, acabar com as estruturas coloniais do racismo, do patriarcado, do colonialismo, dentre outros.

Portanto, para Candau (2020), os diálogos entre esses sujeitos individuais e coletivos, saberes e práticas, na afirmação da perspectiva da justiça social, econômica, cognitiva e cultural na construção dessas relações igualitárias, são promovidos frutiferamente por diálogos interculturais. A autora afirma que não podemos reduzir a escola apenas a ensinar e a instruir para o sucesso de testes padronizados, é necessário que lutemos contra o sequestro da educação. O que a autora quer dizer com a escola sequestrada? É aquela escola que dá ênfase na avaliação e gestão, é a escola que congelou uma lógica produtivista ilimitada, em que não se mede a qualidade e se dá ênfase na cultura da avaliação. Esta lógica também está nas universidades, para além das escolas.

\section{Pela construção de mais brechas decoloniais no combate à violência epistemológica e/ou ao epistemicídio no ensino de História}


Para concluir, precisamos mais uma vez dizer que é necessário oferecer memórias não autoritárias, não excludentes, práticas sociais mais solidárias, falar de sujeitos outros, de práticas solidárias através da história, de práticas e memórias outras, de grupos sobreviventes e resistentes e (re)existentes (WALSH, 2017).

Segundo Boaventura, é importante que busquemos a justiça cognitiva e a justiça epistemológica. Nesse sentido, entendemos que precisamos decolonizar o conhecimento científico escolar, decolonizar a escola, decolonizar o currículo, decolonizar as relações sociais, decolonizar as relações políticas, decolonizar as relações econômicas e decolonizar as relações afetivas atravessadas pelo território escolar, acadêmico e todo o tecido social. Aventurarmo-nos por escavações que nos permitam construir currículos insurgentes que proporcionem que povos oprimidos, silenciados e excluídos pelo capitalismo, pelo patriarcado e pelo colonialismo se reconheçam também na escola, que se sintam incluídos nos currículos.

Construir um currículo de História escolar com maior presença do que Santos (2007) chama de Sociologia das Emergências, ou seja, incluirmos saberes e práticas outras, histórias e memórias dos povos yorubás, bantos, afrodescendentes, asiáticos, bororos, kaingang, guaranis, xacriabás, populações das favelas e periferias urbanas brasileiras, caiçaras, mestiços brasileiros, pequenos agricultores e todos aqueles que se encontram aprisionados em minorias identitárias. Terminar, ou minimizar as Sociologias das Ausências, que produzem não existências. Segundo Boaventura Santos (2007) se produz não existências quando se desqualifica ou silencia ou invisibiliza uma dada instituição, história, grupamento social, ideia insurgente, ou algo semelhante.

Neste sentido, apostamos num ensino de História que construa uma Sociologia das Emergências, para Santos (2002: 258) esta "consiste em substituir o vazio do futuro segundo o tempo linear (um vazio que tanto é tudo como é nada) por um futuro de possibilidades plurais e concretas, simultaneamente utópicas e realistas, que se vão construindo no presente através das actividades de cuidado".

Portanto, estruturas coloniais de poder, precisam ser atacadas segundo o pensamento decolonial e as práticas e pedagogias decoloniais - que são por natureza anticoloniais, antirracistas, antimachistas e anticapitalistas. Nesse sentido, o pensamento decolonial é citado por Arturo Escobar, no trecho a seguir, como um desses caminhos:

examinó las cinco tendencias que considero las más novedosas en los estudios críticos del "desarrollo" en América Latina en los últimos años; las 
cuales incluyen: el pensamiento decolonial, las alternativas al "desarrollo", las transiciones al postextractivismo, la crisis y cambio de modelo civilizatorio y varias perspectivas interrelacionadas que se centran en "la relacionalidad" y "lo comunal". (ESCOBAR, 2014: 16)

Fazer esse diálogo intercultural entre as narrativas, lutas, disputas de histórias e memórias de resistência dos povos que foram subalternizados pelo colonialismo, capitalismo e patriarcado nas aulas e nos livros didáticos de história é uma aposta e um grande desafio. Para tanto precisamos começar por nós mesmos, como já afirmamos, decolonizando nossas concepções de ciência e saber, nossas certezas, por isso a aventura do pensamento decolonial não é só acadêmica, ela é integral/holística, nos envolve entre ser, estar, pensar e lutar, ou melhor, como nos sugere Escobar (2014) no nosso sentipensamento!

Desejamos que mais raps indígenas, ou quem sabe yorubás ou de tantos outros povos - que ficaram submersos pelas Sociologias das Ausências -, tenham o direito de permear e protagonizar narrativas e memórias na história brasileira e de Nossa América; que novas canções ou velhas cantigas invisibilizadas por saberes brancos, cristãos, eurocêntricos, ocidentais e masculinos possam ser ensaiadas, cantadas e escritas para serem lembradas em nossas narrativas e memórias. Assim, praticaremos aprendizagens mais plurais e includentes envolvendo maior justiça epistemológica ou cognitiva.

\section{Referências bibliográficas}

ALBERTI, Verena (2013). Manual de história oral. 3 ed. Rio de Janeiro: FGV.

ARAÚJO, Helena Maria Marques (2017). Educar através das memórias. e-Mosaicos, [S.1.], v. 6, n. 12, p. 214-225, set. ISSN 2316-9303. Disponível em: $<$ https://www.e-publicacoes.uerj.br/index.php/e-

mosaicos/article/view/30260/21462>. Acesso em: 25 jun. 2021. doi:https://doi.org/10.12957/e-mosaicos.2017.30260.

BENJAMIN, Walter (1994). Sobre o conceito da História. In: - Magia e Técnica, Arte e Política. 7. ed. São Paulo, Brasiliense. (Obras Escolhidas, v. 1).

CANCLINI, Néstor Garcia (1997). Culturas Híbridas - estratégias para entrar e sair da modernidade. Tradução de Ana Regina Lessa e Heloísa Pezza Cintrão. São Paulo: EDUSP: 283-350.

CANDAU, Vera Maria (2011). DIFERENÇAS CULTURAIS, COTIDIANO ESCOLAR E PRÁTICAS PEDAGÓGICAS. Currículo sem Fronteiras, v.11, n.2, pp.240-255, Jul/Dez.

CANDAU, Vera Maria (2011). Diferenças Culturais e Educação: construindo caminhos. Rio de Janeiro: Ed. 7 Letras. 
CANDAU, Vera Maria (2020). Diferenças, Educação Intercultural e Decolonialidade: temas insurgentes. Rev. Espaço do Currículo (online), João Pessoa, v.13, n. Especial, p. 678-686, dez. ISSN 1983-1579. Doi: 10.22478/ufpb.19831579.2020v $13 \mathrm{n}$ Especial.54949. http://periodicos.ufpb.br/ojs2/index.php

CANDAU, Vera Maria (Org.) (2009). Educação Intercultural na América Latina: entre concepções, tensões e propostas. Rio de Janeiro: Ed. 7 Letras.

CANDAU, Vera Maria (Org.) (2016). Interculturalizar, descolonizar, democratizar: uma educação "outra"? Rio de Janeiro: 7 Letras.

CAPUTO, Stela Guedes (2012). Educação nos Terreiros: e como a escola se relaciona com crianças de candomblé. Rio de Janeiro: Pallas.

DUSSEL, Enrique (2016). Transmodernidade e interculturalidade: interpretação a partir da filosofia da libertação. Soc. Estado, vol.31 no.1, Brasília jan./abr. Disponível em: < https://doi.org/10.1590/S0102-69922016000100004>. Acesso em: 27 abr. 2021.

ESCOBAR, Arturo (2014). Sentipensar con la tierra. Nuevas lecturas sobre desarrollo, territorio y diferencia. Medellín: Ediciones UNAULA. 184 p. (Colección Pensamiento vivo). ISBN: 978-958-8869-14-8

FREINET, C. (1973). As técnicas Freinet da Escola Moderna. Tradução: Silva Letra. Lisboa: Editorial Estampa. (1998). Ensaios de Psicologia sensível. São Paulo: Martins Fontes.

FREIRE, Paulo (2000). Pedagogia da indignação: cartas pedagógicas e outros escritos. São Paulo: Editora UNESP. Disponível em: $<$ https://nepegeo.paginas.ufsc.br/files/2018/11/Paulo-Freire-Pedagogia-daindigna\%C3\%A7\%C3\%A30.pdf >. Acesso em: 15 abr. 2021.

HALL, Stuart (2006). A identidade cultural na pós-modernidade. Tradução Tomaz Tadeu da Silva e Guaracira Lopes Louro. 11. ed. Rio de Janeiro: DP\&A. Disponível em: <https://leiaarqueologia.files.wordpress.com/2018/02/kupdfcom_identidade-cultural-na-pos-modernidade-stuart-hallpdf.pdf >. Acesso: 20 abr. 2021.

LANDER, Edgardo (Org) (2005). A colonialidade do saber: eurocentrismo e ciências sociais perspectivas latino-americanas. Colección Sur Sur, CLACSO, Ciudad Autónoma de Buenos Aires, Argentina. Disponível em: $<$ https://edisciplinas.usp.br/pluginfile.php/2591382/mod_resource/content/1/colon ialidade_do_saber_eurocentrismo_ciencias_sociais.pdf $>$. Acesso em: 11 abr. 2021.

MIGNOLO, Walter (2000). Histórias locais/projetos globais. Colonialidade, saberes subalternos e pensamento liminar. Tradução Solange Ribeiro de Oliveira. $1^{\text {a }}$ Ed. Belo Horizonte: UFMG.

PAIM, Elison Antonio.; ARAÚJO, Helena Maria Marques (2018). Memórias Outras, Patrimônios Outros e Decolonialidades: Contribuições Teórico-metodológicas para o Estudo de História da África e dos Afrodescendentes e de História dos Indígenas no Brasil. Education policy analysis archives, [S.1.], v. 26, p. 92, july. ISSN 1068-2341. Availableat: <https://epaa.asu.edu/ojs/article/view/3543/2103>.

PAIM, Elison Antonio (2016). Para além das leis: o ensino de culturas e histórias africanas, afrodescendentes e indígenas como decolonização do ensino de história. In: MOLINA, Ana Heloisa, FERREIRA, Carlos. (Orgs.) Entre textos e contextos: caminhos do ensino de História. Curitiba: editora CRV. 556 p.

PEREIRA, Nilton Mullet \& RODRIGUES, Mara Cristina de Matos (2018). BNCC e o Passado Prático: Temporalidades e Produção de Identidades no Ensino de 
História. Arquivos Analíticos de Políticas Educativas, Vol. 26, No. 107. ISSN 1068-2341

POLLAK, Michael (1989). Memória, Esquecimento, Silêncio. Estudos Históricos, Rio de Janeiro, vol. 2, n. 3: 3-15.

PORTO-GONÇALVES, Carlos Walter. (s/d) Entre América e Abya Yala - tensões de territorialidade. Disponível em: https://revistas.ufpr.br/made/article/view/16231/10939. Acesso em: 24 jun. às 14:53.

QUIJANO, Aníbal (2005). Dom Quixote e os moinhos de vento na América Latina. In: Dossiê América Latina. Estudos Avançados 19 (55).

RICOEUR, Paul (2007). A memória, a história, o esquecimento. Campinas, SP: Editora da UNICAMP.

SANTOS, Boaventura Souza (2007). Para além do Pensamento Abissal: Das linhas globais a uma ecologia de saberes. Revista Novos Estudos, n. 79, nov. Disponível em: 〈https://www.scielo.br/pdf/nec/n79/04.pdf >. Acesso em: 10 abr. 2021.

SANTOS, Boaventura Souza (2002). Para uma sociologia das ausências e uma sociologia das emergências. Revista Crítica de Ciências Sociais, 63: 237-280.

SANTOS, Boaventura de Souza; MENESES, Maria Paula (2010). Epistemologias do Sul. São Paulo: Ed. Cortez.

SILVA, Tomaz Tadeu da (2005). Documentos de Identidade: uma introdução às teorias do currículo. Belo Horizonte: Autêntica.

WALSH, Catherine (Ed.) (2013). Pedagogías decoloniales: prácticas insurgentes de resistir, (re)existir y (re)vivir. Tomo I. Quito, Ecuador: Ediciones Abya-Yala.

WALSH, Catherine (Ed.) (2017). Lo pedagógico y lo decolonial: entretejiendo caminos. Pedagogías decoloniales: prácticas insurgentes de resistir, (re)existir y (re)vivir. Tomo II. Quito, Ecuador: Ediciones Abya-Yala.

Artigo recebido em 01 de junho de 2021.

Aprovado em 30 de junho de 2021.

DOI: 10.12957/intellectus.2021.60983 